\title{
Shared and Unique Environmental Factors Determine the Ecology of Methanogens in Humans and Rats
}

Timothy H. J. Florin, B.Sc. (Hons.), M.Sc., M.D., Gu Zhu, M.D., M.P.H., Katherine M. Kirk, B.Sc. (Hons.), Ph.D., and Nicholas G. Martin, B.Sc. (Hons.), Ph.D.

Department of Medicine, University of Queensland and Mater Misericordiae Hospital, and Queensland Institute of Medical Research and Joint Genetics Program, University of Queensland, Brisbane, Queensland, Australia

OBJECTIVE: This study ascertains the relative contributions of genetics and environment in determining methane emission in humans and rats. There is considerable interest in the factors determining the microbial species that inhabit the colon. Methanogens, which are archaebacteria, are an easily detected colonic luminal bacteria because they respire methane. They are present in some but not all human colons and lower animal hindguts. Opinion varies on the nature of the factors influencing this ecology with some studies proposing the existence of host genetic influences.

METHODS: Methane emission was measured in human twin pairs by gas chromatography, and structural equation modeling was used to determine the proportion of genetic and environmental determinants. The importance of the timing of environmental effects and rat strain on the trait of methane emission were ascertained by experiments with cohabiting methanogenic and nonmethanogenic rats.

RESULTS: Analysis of breath samples from 274 adolescent twin pairs and their families indicated that the major influences on the trait of methane emission are the result of shared $(53 \%, 95 \%$ confidence interval 39-61) and unique environmental $(47 \%, 95 \%$ confidence interval 38-56) effects. No significant autosomal genetic effects were detected, but as observed in other studies, men $(37 \%)$ were less likely to excrete methane in their breath than women $(63 \%)$. Investigation of methane emission in rats indicated that environmental effects in this animal are most potent during the weaning period, with stable gut microbial ecology thereafter for some but not all rat strains.

CONCLUSIONS: These results are consistent with shared and unique environmental factors being the main determinants of the ecology of this colonic microbe. (Am J Gastroenterol 2000;95:2872-2879. (C) 2000 by Am. Coll. of Gastroenterology)

\section{INTRODUCTION}

Methanogens are archaebacteria $(1,2)$. Archaebacteria (or archaea) form an ancient microbial lineage, which is a third life form. These microbes are as different from the pro- karyote anaerobic and aerobic (eu)bacteria as these are different from eukaryotes (plants and animals) (2). They are an essential part of luminal intestinal microbial ecosystems, where they respire hydrogen to produce methane (3). Their presence in these ecosystems ensures more complete fermentation of substrates because certain incompletely oxidizing reactions proceed only at low hydrogen concentration $(4,5)$. In the ruminant forestomach, they are the principal hydrogen-consuming bacteria. They are also the principal hydrogen-consuming bacteria in the colons of methanogenic humans, where they reduce flatulence and bloating by the conversion of four volumes of hydrogen gas to one volume of methane gas. They are more efficient at hydrogen consumption than other hydrogen-consuming bacteria in human colons $(6,7)$, and they always outcompete other hydrogenconsuming bacteria in in vitro experiments with nonmethanogenic feces (8).

Although all rumens have significant numbers of methanogens, in the world of the animal hindgut and the human colon, some have it and others do not $(9,10)$. The reasons for their absence or very low number in some colons are unknown. In methane-producing humans, methanogens number $1.6 \times 10^{8}$ to $8 \times 10^{9} / \mathrm{g}$ feces $(11,12)$, but less than $10^{2}$ to $5 \times 10^{6} / \mathrm{g}$ feces in nonmethanogenic humans (12). The carriage of methanogens and methane production are remarkably stable over time. Furthermore, human or animal metabolism does not modify methane, which in humans, is excreted exclusively through breath during the fasting state, as well as by flatus after a fiber-rich substrate load $(13,14)$.

It has been suggested that congenital or taxonomic factors determine methane-producing status in the human large bowel $(15)$ or the lower animal hindgut $(9,16)$, but opinion varies about whether these factors relate to shared early familial environment (15) or to familial genetic influences $(16,17)$.

The present study examines whether methane-producing status (methanogenesis) is determined by environmental or genetic factors. First, we report methane emission data from a cohort of human twins comprising 75 genetically diagnosed monozygotic (MZ), 199 dizygotic (DZ) pairs, and other family members. Second, we report methane emission 
data from cohabitation experiments that involved closed rat colonies, some of which were highly methanogenic and some of which were not. The concordance data and results from genetic modeling in the human twin families exclude all but the smallest genetic influence within same sex subjects, while both the human and animal data indicate that shared environment is the main determinant of the inheritance of methane emission.

\section{MATERIALS AND METHODS}

\section{Human Experiments}

SUBJECTS. Data for the twin study were collected as part of an ongoing longitudinal investigation of melanocytic naevus (mole) development in adolescent twins in Queensland, Australia, the sample and clinical protocol of which have been described elsewhere $(18,19)$. At age 12 and again at age 14, participating twins, their parents, and siblings visited the Queensland Institute of Medical Research. Zygosity of twins was initially established by the physical appearance of the twins and mother's report, but in the absence of complete certainty, genotyping was undertaken using eight independent highly polymorphic DNA markers and three blood groups (ABO, Rh, and MNS). The study was approved by the Queensland Institute of Medical Research Ethics Committee, which is constituted according to National Health and Medical Research Council guidelines.

The present analysis involved $75 \mathrm{MZ}$ (44 female and 31 male) and 199 DZ (54 female, 50 male, and 95 unlike-sex) complete twin pairs and 5 incomplete pairs who first visited the Institute between February and October 1996 (mean age 13.0 yr, SD 1.0 yr). Between February and September 1998, 24 of these twin pairs had also completed their second visit (mean age $14 \mathrm{yr}$, SD $0.20 \mathrm{yr}$ ). The mean age of the 216 mothers (of 230 participants) for whom age data were available at the twins' first visit was $42.1 \mathrm{yr}$, SD $4.8 \mathrm{yr}$, whereas the mean age at the twins' first visit for the 69 fathers (of 73 participants) was $45.0 \mathrm{yr}$, SD $6.1 \mathrm{yr} .129$ siblings (mean age $13.9 \mathrm{yr}$, SD $2.9 \mathrm{yr}$ ) also participated. As a method of estimating the repeatability of the measurement techniques used in this study, breath samples were also obtained from 24 volunteers at the Queensland Institute of Medical Research who were not directly involved in the study, with repeat measurements taken 2 weeks later.

MEASUREMENT OF BREATH METHANE. Methane concentration was measured in end-expiratory breath from each human subject. This was collected in a 25-ml Teflon syringe. Dead space air was excluded by using a partywhistle device $(7,20)$. A contemporaneous sample of atmosphere was gathered with each collection. Once trapped, the gas was syringed into negatively pressurized $25-\mathrm{ml}$ glass Wheaton bottles for storage. (The Wheaton bottles, which were labeled with subject's code number and date of collection, were prepared by stopping with gas tight butyl rubber plugs [Wheaton, Millville, NJ], washing with argon gas, and then evacuating argon by twice fully drawing back an empty 25-ml Teflon syringe and discharging its contents to atmosphere.) Methane was measured within $4 \mathrm{wk}$ of collection in 18 batches of 20-50 samples. Measurement was by gas chromatography with flame ionization detection (7, 20) (Packard GC model 428, Delft, Holland, with a 4-mm by 2-m glass column packed with Poropak Q, carrier gas $\mathrm{N}_{2}$, injection temperature $25^{\circ} \mathrm{C}$, oven temperature $50^{\circ} \mathrm{C}$, and detector temperature $200^{\circ} \mathrm{C}$ ). Storage of an argon standard in the glass Wheaton bottle was stable: mean recovery after 3 months of storage of a known 57 ppm methane standard (Commonwealth Industrial Gas, Sydney, Australia) was $101 \%$ (SD 3). Mean atmospheric $\mathrm{CH}_{4}$ was $4.2 \mathrm{ppm}$ (SD 0.2). Breath methane was calculated by subtracting the atmosphere value for a particular day from the methane concentration in breath samples collected on the same day.

STATISTICAL TECHNIQUES AND ANALYSES. The distribution of $\mathrm{CH}_{4}$ was positively skewed in this sample. Because the analytical methods used here required the data to be normally distributed, transformation of the data were required. Previous studies that analyzed breath methane have used a simple "excreters versus nonexcreters" scoring method for methane emission (17, 21, 22-25). Unfortunately, information may be lost in reducing data to a twopoint (dichotomous) scoring system. Therefore, in this study, a logarithmic transformation $\left(\log _{\mathrm{e}}\left(\mathrm{CH}_{4}+1\right)\right)$ was applied before analysis of the data. To facilitate comparisons with previous literature, two different two-point scoring methods (no $\mathrm{CH}_{4}$ /any $\mathrm{CH}_{4}$ and $\leq 0.99 \mathrm{CH}_{4} / \geq 1.00 \mathrm{CH}_{4}$ ppm above ambient) were also considered. Pearson correlations, pairwise concordance rates, and other basic statistical tests have been performed using SPSS 8.0. Tetrachoric correlations (on the assumption of an underlying normal liability to methanogenesis) were calculated from $2 \times 2$ contingency tables using PRELIS 2.1 (26).

Although significant twin correlations establish the fact that there is familial aggregation for the measures of interest, they do not distinguish between the possible mechanisms by which this familial likeness may arise. One useful method for achieving this is by structural equation modeling as implemented in LISREL, Mx (Richmond, VA), or similar packages (27). One can conceive of several causes of variation, two of which (genetic influences and shared environment) make family members more alike than random pairs of individuals, and one of which (unique environmental experiences) makes MZ twins and siblings different. The task then is to decide which combination of these parameters provides the simplest explanation for the observed pattern of $\mathrm{MZ}$ and DZ twin correlations without compromising the fit of the model to the data. Nonidentical twins, like siblings, share on average only half their genes, whereas MZ twins are genetically identical. Therefore, a much greater resemblance of $\mathrm{MZ}$ twins than $\mathrm{DZ}$ twins for a given trait of interest would indicate the presence of genetic influences on that trait. By contrast, an absence of genetic influences 
Table 1. Mean, SD, Maximum $\mathrm{CH}_{4}$ Measurement for Twins, Their Parents, and Siblings for Visit 1, and Twins and Parents for Visit 2

\begin{tabular}{|c|c|c|c|c|c|c|c|c|}
\hline & \multicolumn{2}{|c|}{ Twins } & \multicolumn{2}{|c|}{ Parents } & \multicolumn{2}{|c|}{ Siblings } & \multicolumn{2}{|c|}{ Volunteers } \\
\hline & Male & Female & Fathers & Mothers & Brothers & Sisters & Male & Female \\
\hline \multicolumn{9}{|l|}{ Visit 1} \\
\hline Mean & 4.34 & 4.78 & 4.50 & 7.91 & 4.08 & 4.98 & 2.00 & 4.14 \\
\hline SD & 9.80 & 9.62 & 8.82 & 12.77 & 7.69 & 8.50 & 1.73 & 7.50 \\
\hline Maximum & 61 & 80 & 50 & 90 & 40 & 38 & 3 & 30 \\
\hline $\mathrm{N}$ & 259 & 294 & 73 & 230 & 69 & 58 & 3 & 21 \\
\hline \multicolumn{9}{|l|}{ Visit 2} \\
\hline Mean & 2.80 & 2.42 & 9.38 & 9.88 & - & - & 6.50 & 9.06 \\
\hline SD & 3.87 & 4.14 & 8.22 & 10.61 & - & - & 5.77 & 11.39 \\
\hline Maximum & 13 & 12 & 20 & 28 & - & - & 11 & 34 \\
\hline $\mathrm{N}$ & 23 & 25 & 4 & 20 & - & - & 3 & 18 \\
\hline
\end{tabular}

$\mathrm{CH}_{4}$ measurements in ppm. For each group, minimum $\mathrm{CH}_{4}$ was $0 \mathrm{ppm}$. Results for the volunteers are shown in the last columns. $\mathrm{N}=$ number of participants at each visit.

would be indicated by the degree of similarity between $\mathrm{MZ}$ twins being the same as the degree of similarity between DZ twins and also nontwin siblings. Where information is available from males and females in MZ twin pairs and DZ same-sex and opposite-sex twin pairs, modeling techniques can be extended to include considerations of whether there are sex differences in the etiology of the phenotype. Structural modeling for this study has been implemented using Mx (28), and the Akaike Information Criterion has been used to compare the parsimony of the various models (29).

\section{Animal Experiments}

RATS. Rats were bred and housed at the University of Queensland Central Animal Breeding House (UQCABH) between 1995 and 1998. Inbred JC-Lewis and DA, IncisorAbsent (IA), and outbred Wistar rats were kept in closed same sex colonies. Animal feces were screened for methane emission at 2- to 4-wk intervals after weaning. Significant methanogenesis was first noted at about $10 \mathrm{wk}$ after weaning in agreement with Maczulak et al. (30).

Some mature IA rats were highly methanogenic $\left(\mathrm{IA}^{+}\right.$, fecal methane emission $>550 \mathrm{ppm})$, whereas others remained nonmethanogenic $\left(\mathrm{IA}^{-}\right.$, fecal methane emission $<10 \mathrm{ppm}$ ). UQCABH adult Wistar and JC-Lewis rats developed intermediate methanogenesis. UQCABH DA rat colonies were nonmethanogenic. Methanogens were confirmed in rat feces by fluorescence microscopy (7).

Breeding pairs of the methanogenic $\mathrm{IA}^{+}$and nonmethanogenic $\mathrm{IA}^{-}$rats were established and bred true in closed colonies for six generations. Some $\mathrm{IA}^{+}$rats were kept in the same cage for 4 wk with same gender adult $\mathrm{IA}^{-}$, DA, JC, and Wistar rats, separated, and methane emission studied. In other experiments, DA pups were raised with $\mathrm{IA}^{+}$mothers before weaning at 21 days and then were maintained in separate same sex colonies.

FECAL METHANE EMISSION. Fresh rat feces were collected at the same time in the morning at 2- to 4-wk intervals, homogenized and buffered in deoxygenated $0.1 \mathrm{~N}$ HEPES pH 7.0 and made up to a final concentration of $10 \%$ $\mathrm{wt} / \mathrm{vol}$ under an atmosphere of argon. Anaerobic cultures of the fecal suspensions were grown at $37^{\circ} \mathrm{C}$ in $15-\mathrm{ml}(8 \mathrm{ml}$ of suspension/7 $\mathrm{ml}$ of headspace with argon under pressure) butyl rubber stoppered glass Wheaton bottles (7). Headspace methane concentration was measured at $4 \mathrm{~h}$ using the Packard gas chromatograph.

\section{Ethics}

The animal experiments were approved by the University of Queensland Ethics Committee.

\section{RESULTS}

\section{Human Experiments}

Five hundred and eighty-two females and 401 males from the twin families were studied (sex was not recorded for two siblings). Females were more likely to excrete methane in their breath with $63 \%$ females versus $37 \%$ males having any methane present in their breath $(p=0.012)$. Mean breath methane (range) was $6.03 \mathrm{ppm}(0.0-90.0 \mathrm{ppm})$ for females and $4.32 \mathrm{ppm}(0.0-61.0 \mathrm{ppm})$ for males $(p=0.001)$.

TEST-RETEST. Means, maximum breath $\mathrm{CH}_{4}$, and standard deviations for twins, their parents, and siblings at visit 1 , and the twins and their parents at visit 2 , are shown in Table 1. Comparison of individuals' item responses collected at separate times provides an indicator of the stability of the measures being used over the relevant time interval. For the 21 volunteers for whom two measurements were made, the test-retest correlation over the 2 -wk interval was 0.89 for the log-transformed data and 0.63 for the two two-point scoring methods, indicating a strong short-term stability. High correlations within individuals over an approximately 2 -yr interval were also obtained for the 72 individuals (48 twins and 24 parents) who completed a second visit ( $r=0.85$ for logarithmic transformation; $r=$ 0.62 for the dichotomous scoring method of no $\mathrm{CH}_{4}$ /any $\mathrm{CH}_{4} ; r=0.87$ for the dichotomous scoring method of $\mathrm{CH}_{4}$ $\leq 0.99 / \mathrm{CH}_{4} \geq 1.00$ ). Both these repeatability/stability studies point to the value of an appropriately transformed continuous measure rather than reducing the data to two-point scales. 
Table 2. Correlations for Logarithmically Transformed $\mathrm{CH}_{4}$ Measurements Between Various Twin Groups and Other Family Relationships at Visit 1

\begin{tabular}{|c|c|c|c|c|c|c|c|c|}
\hline \multirow[b]{2}{*}{ Relationship } & \multirow[b]{2}{*}{$\mathrm{N}$} & \multirow{2}{*}{$\frac{\log _{\mathrm{e}}\left(\mathrm{CH}_{4}+1\right)}{\text { Correlation }}$} & \multicolumn{3}{|c|}{$\left(\right.$ no $\mathrm{CH}_{4}$ /any $\left.\mathrm{CH}_{4}\right)$} & \multicolumn{3}{|c|}{$\left(\mathrm{CH}_{4} \leq 0.99 / \mathrm{CH}_{4} \geq 1.00\right)$} \\
\hline & & & $\begin{array}{c}\text { Pairs } \\
\text { Concordant }\end{array}$ & $\begin{array}{c}\% \\
\text { Concordant }\end{array}$ & Correlation & $\begin{array}{c}\text { Pairs } \\
\text { Concordant }\end{array}$ & $\begin{array}{c}\% \\
\text { Concordant }\end{array}$ & Correlation \\
\hline MZ female twin pairs & 44 & 0.356 & $34(17+17)$ & 77.2 & 0.558 & $28(17+11)$ & 63.6 & 0.283 \\
\hline MZ male twin pairs & 31 & 0.589 & $23(14+9)$ & 74.2 & 0.477 & $25(19+6)$ & 80.7 & 0.530 \\
\hline All MZ twin pairs & 75 & 0.450 & $57(31+26)$ & 76.0 & 0.524 & $53(36+17)$ & 70.7 & 0.385 \\
\hline DZ female twin pairs & 54 & 0.572 & $38(21+17)$ & 70.4 & 0.412 & $37(24+13)$ & 68.5 & 0.344 \\
\hline DZ male twin pairs & 50 & 0.512 & $40(28+12)$ & 80.0 & 0.554 & $37(28+9)$ & 74.0 & 0.393 \\
\hline DZ opposite sex twin pairs & 95 & 0.601 & $74(44+30)$ & 77.9 & 0.548 & $77(53+24)$ & 81.1 & 0.583 \\
\hline All DZ twin pairs & 199 & 0.570 & $152(93+59)$ & 76.4 & 0.513 & $151(105+46)$ & 75.9 & 0.470 \\
\hline Male twins with father & 62 & 0.552 & $47(21+26)$ & 75.8 & 0.559 & $46(28+18)$ & 74.2 & 0.539 \\
\hline Male twins with mother & 225 & 0.257 & $148(89+59)$ & 65.8 & 0.315 & $142(98+44)$ & 63.2 & 0.240 \\
\hline Female twins with father & 84 & 0.350 & $53(28+25)$ & 63.1 & 0.256 & $55(37+18)$ & 65.5 & 0.255 \\
\hline Female twins with mother & 230 & 0.194 & $138(60+78)$ & 60.0 & 0.243 & $131(70+61)$ & 57.0 & 0.197 \\
\hline Siblings with father & 33 & 0.265 & $20(10+10)$ & 60.6 & 0.213 & $23(14+9)$ & 69.7 & 0.380 \\
\hline Siblings with mother & 117 & 0.425 & $74(37+37)$ & 63.2 & 0.272 & $79(45+34)$ & 67.5 & 0.359 \\
\hline Spouses & 43 & 0.277 & $28(8+20)$ & 65.1 & 0.250 & $24(10+14)$ & 55.8 & 0.139 \\
\hline
\end{tabular}

Correlations, pairwise concordances, and numbers of concordant pairs (concordant unaffected + concordant affected) for the different family relationships are also shown for the two different two-point (dichotomous) scoring methods considered. Aggregate correlations for MZ and DZ twins are shown in bold type.

CORRELATIONS BETWEEN FAMILY MEMBERS. Correlations (and concordances) between MZ and DZ twins, and between twins and their other relatives, are shown in Table 2 for the three data transformations mentioned. It is evident for all scoring methods that the correlations (or concordances) between the MZ twins are approximately equal to those for DZ twins. The magnitude of correlations (or concordances) between twins and parents, siblings and parents, and spouses was generally smaller. This indicates that shared environmental effects are important in the etiology of methanogenesis, and that genetic effects are relatively unimportant. Correlations between family members for breath methane at visit 1 are also shown in Figure 1.

STRUCTURAL EQUATION MODELING. Results of various structural equation models obtained from the analysis of the logarithmically transformed $\mathrm{CH}_{4}$ data for twins are shown in Table 3. Twenty-four models were investigated but only the five most relevant are shown. Comparison of model 3 with models 1 or 2 indicates that there is no significant difference between males and females in the relative contributions of genetic, shared environment, and unique environmental effects, as the parameters for males and females can be equated without significantly worsening the fit of the model $\left(\chi_{3}^{2}=0.70\right)$. Model 4 compared with models 2 or 3 demonstrates that shared environmental effects cannot be removed from the structural equation model without significant reduction in model fit $\left(\chi_{1}^{2}=24.06\right)$, whereas a comparison of model 5 with models 2 and 3 indicates that genetic effects are not significant for either males or females $\left(\chi_{1}^{2}=0.00\right)$. This final model also pro- vides an extremely good fit to the data $(p=0.585)$, and indicates that approximately 53\% of variation in methanogenesis in humans is attributable to shared environmental effects, with the remaining $47 \%$ of the variation arising from unique environmental influences. Confidence intervals (95\% CI) for genetic, shared environment, and unique environmental effects are $0.00-0.18,0.39-0.61$, and $0.38-$ 0.56 , respectively. Similar results were obtained using the other data transformation methods.

\section{Rat Methane Emission}

Significant methane emission was only detected in mature $(>10 \mathrm{wk})$ rats. Rats in closed colonies that were not methanogenic by $16 \mathrm{wk}$ after weaning did not become methanogenic. Methane emission did not depend on gender and rats that became methanogenic remained so for the duration of the study.

For mature $\mathrm{IA}^{+}$rats (six generations, $\mathrm{n}=108$ ), methane emission in 4-h fecal cultures was $>550$ ppm (range, 555$44,000 \mathrm{ppm})$. For closed colonies of mature Wistar $(\mathrm{n}=10)$ or JC-Lewis rats $(\mathrm{n}=8)$, methane emission was intermediate with headspace methane ranging from 20 to $280 \mathrm{ppm}$ in 4-h fecal cultures. Methane emission never exceeded 15 ppm in closed colony mature DA rats $(n=10)$. Methane emission never exceeded $10 \mathrm{ppm}$ in closed colony mature $\mathrm{IA}^{-}$rats (six generations, $\mathrm{n}=95$ ).

When $\mathrm{IA}^{+}$male or female adult rats were cohabited with same age and gender $\mathrm{IA}^{-}$, DA, JC-Lewis, or Wistar rats for 1 month, the cohabited $\mathrm{IA}^{-}$rats all became methanogenic, but most DA rats remained nonmethanogenic and methane emission did not change significantly in mature JC-Lewis or 


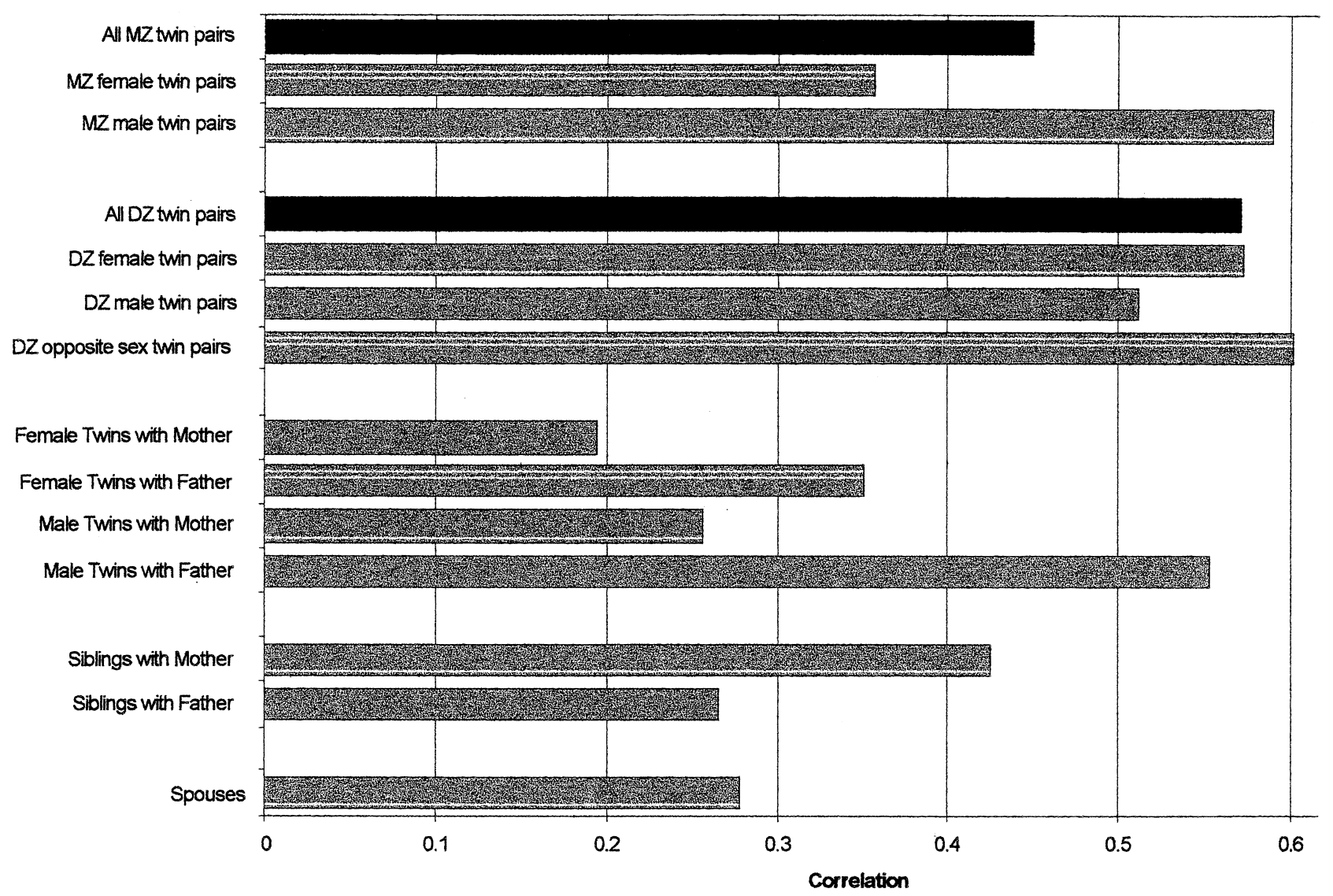

Figure 1. Correlations for logarithmically transformed $\mathrm{CH}_{4}$ measurements between various twin groups and other family relationships at visit 1. Aggregate correlations for MZ and DZ twins are shown as darker bars.

Wistar animals. Table 4 shows the methane emission data from cohabitation experiments with male rats. The female cohabitation results were similar (data not shown).

Although cohabitation of adult Wistar or DC with methanogenic $\mathrm{IA}^{+}$did not affect the methane emission trait of the former, when four Wistar or DA pups were fostered with $\mathrm{IA}^{+}$mothers, weaned and then maintained in closed colonies, they grew into highly methanogenic adult rats $(n=2$ experiments). Methane emission was in the foster mother $\mathrm{IA}^{+}$rats 2,500-15,500 ppm, in the same $\mathrm{IA}^{+}$mothers after weaning $11,750-32,050 \mathrm{ppm}$, in Wistar adults after rearing as pups with the foster $\mathrm{IA}^{+}$mothers $5,840-8,000 \mathrm{ppm}(v \mathrm{~s}$ contemporaneous mature Wistar adult controls $20-55 \mathrm{ppm}$ ), in DA adults after rearing as pups in the presence of foster $\mathrm{IA}^{+}$mothers 900-3,400 ppm (contemporaneous DA controls 3-7 ppm).

\section{DISCUSSION}

The principal findings of this study are the overall similarity between correlations or concordances of methane emission in $\mathrm{MZ}$ and $\mathrm{DZ}$ twins, the generally smaller correlations or concordances between parent-child and spouse pairs, the female bias in human methanogenesis, the transfer of methanogenesis in only some cohabiting adult rat strains, the transfer of methanogenesis to all pups reared with

Table 3. Structural Equation Models for $\log _{e}\left(\mathrm{CH}_{4}+1\right)$, With Genetic (A), Shared Environment (C), and Unique Environment (E) Parameters for Female and Male Subjects

\begin{tabular}{|c|c|c|c|c|c|c|c|c|c|c|}
\hline \multirow[b]{2}{*}{ Model } & \multicolumn{3}{|c|}{ Females } & \multicolumn{3}{|c|}{ Males } & \multicolumn{3}{|c|}{ Model Fit } & \multirow[b]{2}{*}{ AIC } \\
\hline & A & $\mathrm{C}$ & $\mathrm{E}$ & A & $\mathrm{C}$ & $\mathrm{E}$ & $\chi^{2}$ & df & $\begin{array}{c}p \\
\text { Value }\end{array}$ & \\
\hline 1 & 0.006 & 0.499 & 0.495 & 0.048 & 0.546 & 0.406 & 10.60 & 9 & 0.305 & -7.41 \\
\hline 2 & 0.000 & 0.503 & 0.497 & - & 0.572 & 0.428 & 10.63 & 10 & 0.387 & -9.37 \\
\hline 3 & $0.000^{*}$ & $0.534^{\dagger}$ & $0.466^{\ddagger}$ & $0.000 *$ & $0.534^{\dagger}$ & 0.466 & 11.30 & 12 & 0.503 & -12.70 \\
\hline 4 & $0.597 *$ & - & $0.403^{\ddagger}$ & $0.597 *$ & - & $0.403^{\ddagger}$ & 36.26 & 13 & 0.001 & 10.26 \\
\hline 5 & - & $0.534^{\dagger}$ & 0.466 & - & $0.534^{\dagger}$ & 0.466 & 11.30 & 13 & 0.585 & -14.70 \\
\hline
\end{tabular}

Superscripts within models indicate parameters constrained to be equal to one another. The simplest model adequately explaining the observed data is indicated in bold type. 
Table 4. Results of Cohabitation for 1 Month of Single Male $\mathrm{IA}^{+}$Rats With Either Four Male Mature IA ${ }^{-}$, DA, JC-Lewis, or Wistar Rats

\begin{tabular}{|c|c|c|c|c|c|c|}
\hline \multirow{2}{*}{$\begin{array}{l}\text { Cohabiting } \\
\text { Rat Strain }\end{array}$} & \multirow[b]{2}{*}{ Days } & \multicolumn{5}{|c|}{ Methane Emission (ppm) } \\
\hline & & $\mathrm{IA}^{+}$rat 1 & $\mathrm{IA}^{-}$rat 1 & $\mathrm{IA}^{-}$rat 2 & $\mathrm{IA}^{-}$rat 3 & $\mathrm{IA}^{-}$rat 4 \\
\hline \multirow{3}{*}{$\mathrm{IA}^{-}$} & $\mathrm{T}=0$ & 15,500 & 3 & 6 & 4 & 9 \\
\hline & $\mathrm{T}=28$ & 625 & 200 & 550 & 150 & 8,000 \\
\hline & $\mathrm{T}=56$ & 13,000 & 15,550 & 2,300 & 8,500 & 7,500 \\
\hline \multirow{4}{*}{ DA } & & $\mathrm{IA}^{+}$rat 2 & DA rat 1 & DA rat 2 & DA rat 3 & DA rat 4 \\
\hline & $\mathrm{T}=0$ & 1,200 & 5 & 2 & 10 & 6 \\
\hline & $\mathrm{T}=28$ & 3,200 & 6 & 2 & 9 & 450 \\
\hline & $\mathrm{T}=56$ & 9,550 & 10 & 4 & 2 & 1950 \\
\hline \multirow{4}{*}{ JC-Lewis } & & $\mathrm{IA}^{+}$rat 3 & $\begin{array}{c}\text { JC-Lewis } \\
\text { rat } 1\end{array}$ & $\begin{array}{c}\text { JC-Lewis } \\
\text { rat } 2\end{array}$ & $\begin{array}{c}\text { JC-Lewis } \\
\text { rat } 3\end{array}$ & $\begin{array}{c}\text { JC-Lewis } \\
\text { rat } 4\end{array}$ \\
\hline & $\mathrm{T}=0$ & 8,050 & 160 & 55 & 320 & 110 \\
\hline & $\mathrm{T}=28$ & 5,550 & 130 & 65 & 140 & - \\
\hline & $\mathrm{T}=56$ & 4,200 & 68 & 55 & 150 & 200 \\
\hline \multirow{4}{*}{ Wistar } & & $\mathrm{IA}^{+}$rat 4 & Wister rat 1 & Wistar rat 2 & Wistar rat 3 & Wistar rat 4 \\
\hline & $\mathrm{T}=0$ & 6,900 & 20 & 55 & 110 & - \\
\hline & $\mathrm{T}=28$ & 4,975 & 230 & 40 & 45 & 125 \\
\hline & $\mathrm{T}=56$ & 7,500 & 80 & 56 & 85 & 95 \\
\hline
\end{tabular}

Fecal methane emission $(\mathrm{ppm})$ was measured before cohabitation $(\mathrm{T}=0)$, at the end of 28 days' cohabitation $(\mathrm{T}=28)$, and after a further 28 days' separation $(\mathrm{T}=56)$.

methanogenic mothers, and the dominance of methanogenic metabolism in the cohabitation experiments.

Hackstein et al. (16) concluded from the study of five Dutch and German families that the trait of "methane emission" segregates as an autosomal dominant character. A much larger study of segregation of methane excretion in twins (17), which relied on physiognomy only to establish type of twin zygosity, found similar concordance rates for methane excretion between MZ (68\%) and DZ (69\%) twins, but quotes intrapair correlations of methane excretion of 0.536 and 0.155 for $\mathrm{MZ}$ and $\mathrm{DZ}$ twin pairs, respectively. This anomalous result might possibly be explained by failure to use a logarithmic transformation. (A single very high value in one individual of a DZ twin pair could substantially reduce the correlation coefficient but not similarly affect the tetrachoric concordance estimate, the latter relevant only to data scored on two-point scales.) These correlations were then interpreted as a result of multifactorial non-Mendelian genetic effects (17). The present twin study, which is three times larger than the study by Flatz et al. (17), analyzed continuous data as well as data transformed to two-point scoring methods, and used genetic markers to establish zygosity. This study found both the correlations and the concordance rates for methane emission to be similar for MZ and DZ twins. (The pairwise concordance rates in this study (no $\mathrm{CH}_{4}$ /any $\mathrm{CH}_{4}$ ) for $\mathrm{MZ}$ and $\mathrm{DZ}$ twin pairs were $76.0 \%$ and $76.4 \%$, respectively, corresponding to correlations in liability of 0.52 and 0.51 .)

Equal concordance of an observed trait in $\mathrm{MZ}$ and $\mathrm{DZ}$ twin pairs, whether the concordance rate is high or low, suggests a shared environmental influence rather than genetic effects, because, if genetic influence is paramount, then the concordance rate should be higher in MZ twins. This is because DZ twins share, on average, only half their genes. MZ twin pairs have identical genes, except that random $\mathrm{X}$-inactivation during embryogenesis in females leads to different patterns of X-chromosomal mosaicism and there are differences attributable to somatic gene rearrangement that occurs during $\mathrm{T}$ - and B-cell ontogeny of the immune system (31).

Structural equation modeling of the twin data (Table 3) confirmed that the similar correlations or concordance rates are consistent with effects approximately equal to shared environment $(53 \%, 95 \%$ CI 39-61) and unique environment $(47 \%, 95 \%$ CI 38-56). Genetic effects were not significant (parameter estimate $0.00 \%, 95 \%$ CI 0-18).

A female bias $(p=0.012)$ for methanogenesis $(63 \%$ females vs $37 \%$ males), which has been found in most studies $(6,17,21,22,32)$, is unlikely to be a chance finding. The modeling, although distinguishing genetic and environmental effects within same sex subjects, cannot discriminate between genetic and behavioral effects that associate with the $\mathrm{Y}$ chromosome (or conversely with the X chromosome). Male genetic or behavioral effects may influence mechanisms that control methanogenesis. For example, males have on average faster colonic transit $(22,23)$ that would dilute methanogens, which are extremely slow growing anaerobes whose carriage is favored by slow transit. Also, sex differences in the enterohepatic circulation of bile acid $(23,33,34)$ could influence carriage of methanogens because bile acid has been shown to inhibit methanogenesis (7, 20). Bond et al. (15) noted that it was always the mother who was a methane producer in seven families where it was found that a child and only one of the parents were methane producers. This might suggest the hypothesis that it is intensity of maternal contact during breastfeeding or other activity in infancy that determines methane-producing status. However, our data do not support this hypothesis (Table 
2 and Fig. 1). On the contrary, it appears that paternal-infant contact behavior is a more important determinant of methane producer status in late twentieth century Australian society.

In the animal cohabitation experiments, the dominant environmental effect is most potent in the weaning period. This is when the normal colonic microbial flora becomes established (35). Once established, the microbial ecology is remarkably stable and prevents colonization of other species or subspecies $(36,37)$. This is especially true for methanogens. Thus, pups accrued and retained the methane emission trait of their true or foster "mothers" and $\mathrm{IA}^{+}$and $\mathrm{IA}^{-}$rats bred true for six generations in the period of the study. Once methanogenic, no animal lost the trait over the 2-yr study period. Moreover, on no occasion did a methanogenic adult rat that cohabited with a nonmethanogenic rat, lose the methane emission trait, although a temporary dilution of the trait occurred in some $\mathrm{IA}^{+}$adults (Table 4). Thus, once established in the microbial ecology, these hydrogen-consuming bacteria, which dominate bacterial hydrogen consumption (8), remain for the duration (38). They are not substrate limited-their principal carbon substrate, $\mathrm{CO}_{2}$, is plentiful in the colon-and their presence ensures more complete fermentation $(4,5)$. Conversely, some but not all adult rat strains having been colonized with a nonmethanogenic microbial flora, became methane producing in cohabitation experiments (Table 4). Hackstein and Stumm (9) also found that cohabitation of a methanogen-bearing arthropod species with a similar but nonmethanogen-bearing species sometimes, but not always, resulted in transfer of methanogens to that species. Where methanogens failed to transfer, this was despite similar diet and an apparently similar microbial ecology that performs the colon or hindgut fermentation in rats or arthropods, respectively. Although this argues for the stability of gut microbial ecology—an environmental phenomenon determined in the weaning period-it is difficult to completely exclude a host genetic effect that protects some microbial ecologies to make them more stable and resistant to change than others.

In conclusion, the present study demonstrates that the main factors that prevent the occurrence of methanogenesis in some animal hindguts or human colons are shared and unique environmental factors, not genetic factors. These factors are most strongly operative during the postweaning period. The precise nature of the microbial and host ecological factors that prevent colonization with methanogens remains an enigma.

\section{ACKNOWLEDGMENTS}

The authors gratefully acknowledge Jim O'Leary and Ivor Harris from the University of Queensland Central Animal Breeding House at Pinjarra Hills for enthusiastic help with the animal work, Ann Eldridge and Marlene Grace from the Queensland Institute of Medical Research who collected breath samples from twins, and Karen Walmesley of the
Department of Medicine who performed the $\mathrm{CH}_{4}$ measurements. Dr. Timothy Florin was supported by the NHMRC for part of this work.

Reprint requests and correspondence: Dr. Timothy H. J. Florin, Department of Medicine, University of Queensland, Mater Misericordiae Hospital, South Brisbane 4101, Queensland, Australia.

Received Jan. 26, 2000; accepted May 15, 2000.

\section{REFERENCES}

1. Konig H, Stetter KO. Archaeobacteria. In: Staley JT, ed. Bergey's manual of systematic bacteriology, vol. 3. Baltimore: Williams and Wilkins, 1989:2171-211.

2. Woese CR, Kandler O, Wheelis ML. Towards a natural system of organisms: Proposal for the domains of Archaea, Bacteria and Eucarya. Proc Natl Acad Sci USA 1990;87:4576-79.

3. Miller T, Wolin M. Methanogens in human and animal intestinal tracts. System Appl Microbiol 1986;7:223-9.

4. Wolin M, Miller T. Carbohydrate fermentation. In: Hentges D, ed. Human intestinal microflora in health and disease. New York: Academic Press, 1983:147-65.

5. Thauer R. Limitation of microbial $\mathrm{H}_{2}$ formation via fermentation. In: Schegel HG, Bornea J, eds. Microbial energy conversion. Gottingen: Erich Golt KG, 1976:201-4.

6. Bjorneklett A, Jenssen E. Relationships between hydrogen and methane production in man. Scand J Gastroenterol 1982;17: 985-92.

7. Florin THJ, Jabbar IA. A possible role for bile in the control of methanogenesis and accumulation of hydrogen gas in the human colon. J Gastroenterol Hepatol 1994;9:112-7.

8. Strocchi A, Furne J, Ellis C, et al. Competition for hydrogen by human fecal bacteria: Evidence for the predominance of methanobacteria. Gut 1991;32:1498-501.

9. Hackstein J, Stumm C. Methane production in terrestial arthropods. Proc Natl Acad Sci USA 1994;91:5441-5.

10. Segal I, Walker A, Lord S, et al. Breath methane and large bowel cancer risk in contrasting African populations. Gut 1988;29:608-13.

11. Pochart P, Lemann F, Flourie B, et al. Pyxigraphic sampling to enumerate methanogens and anaerobes in the right colon of healthy humans. Gastroenterology 1993;105:1281-5.

12. Oufir LE, Flourie B, Varannes SB, et al. Relations between transit time, fermentation products, and hydrogen consuming flora in healthy humans. Gut 1996;38:870-77.

13. Christl S, Murgatroyd P, Gibson G, et al. Production, metabolism, and excretion of hydrogen in the large intestine. Gastroenterology 1992;102:1269-77.

14. Hammer H. Colonic hydrogen absorption: Quantification of its effect on hydrogen accumulation caused by bacterial fermentation of carbohydrates. Gut 1993;34:818-22.

15. Bond J, Engel R, Levitt M. Factors influencing pulmonary methane excretion in man. J Exp Med 1971;133:572-88.

16. Hackstein J, Alen TV, Camp HOD, et al. Intestinal methogenesis in primates-a genetic and evolutionary approach. Dtsch tierarzl Wschr 1995;102:152-4.

17. Flatz G, Czeizel A, Metneki J, et al. Pulmonary hydrogen and methane excretion following ingestion of an unabsorbable carbohydrate: A study of twins. J Ped Gastroenterol Nutr 1985;4:936-41.

18. Aitken J, Green A, Eldridge A, et al. Comparability of naevus counts between and within examiners, and comparison with computer image analysis. Br J Cancer 1994;69:487-91.

19. McGregor B, Pfitzner J, Zhu G, et al. Genetic and environ- 
mental contributions to size, colour, shape and other characteristics of melanocytis naevi in a sample of adolescent twins. Genet Epidemiol 1999;16:40-53.

20. Florin THJ, Woods H. Inhibition of methanogenesis by human bile. Gut 1995;37:418-21.

21. Haines A, Imeson J, Wiggins H. Relation of breath methane with obesity and other factors. Int J Obesity 1984;8:675-80.

22. Stephen A, Wiggins H, Englyst H, et al. The effect of age, sex and level of intake of dietary fibre from wheat on large bowel function in thirty healthy subjects. Br J Nutr 1986;56:349-61.

23. McKay L, Eastwood M, Brydon W. Methane excretion in man-a study of breath, flatus and feces. Gut 1985;26:69-74.

24. Peled Y, Weinberg D, Hallak A, et al. Factors affecting methane production in humans. Dig Dis Sci 1987;32:267-71.

25. Hudson M, Tomkins A, Wiggins H, et al. Breath methane excretion and intestinal methanogenesis in children and adults in rural Nigeria. Scand J Gastroenterol 1993;28:993-8.

26. Jöreskog KG, Sörbom D. New features in PRELIS 2 and LISREL 8. Chicago: Scientific Software Inc., 1993.

27. Neale M, Cardon L. Methodology for genetic studies of twins, and families. Dortrecht: Kluwer Academic Publishers, 1992.

28. Neale M. Mx: Statistical modelling, 4th ed. Richmond, VA: Dept. Psychiatry, Virginia Institute for Psychiatric and Behavioral Genetics, 1997.

29. Akaike H. Factor analysis and AIC. Psychometrika 1987;52: 317-32.
30. Maczulak A, Wolin M, Miller T. Increase in colonic methanogens and total anaerobes in aging rats. Appl Environ Microbiol 1989;55:2468-73.

31. Gregersen P. Discordance for autoimmunity in monozygotic twins: Are "identical" twins really identical? Arthritis Rheum 1993;36:1185-92.

32. Pitt P, Bruijn KD, Beeching M, et al. Studies on breath methane: The effect of ethnic origins and lactulose. Gut 1980; 21:951-9.

33. Lampe J, Fredstom S, Slavin J, et al. Sex differences in colonic function: A randomised trial. Gut 1993;34:531-6.

34. Turley S, Schwarz M, Spady D, et al. Gender-related differences in bile acid, and sterol metabolism in outbred CD-1 mice fed low- and high-cholesterol diets. Hepatology 1998;28: $1088-94$.

35. Cheu H, Brown D. Breath hydrogen excretion in the premature neonate. Am J Dis Child 1990;144:197-202.

36. Sears H, Brownlee I, Uchiyama J. Persistence of individual strains of Escherichia coli in the intestinal tract of man. J Bacteriol 1950;59:293-8.

37. Borriello S, Barcaly P. An in-vitro model of colonisation resistance to Clostridium difficile infection. J Med Microbiol 1986;21:299-309.

38. Miller T, Wolin M. Stability of Methanibrevibacter smithii in the microbial flora excreted from the large bowel. Appl Environ Microbiol 1983;45:317-8. 